INSIGHTS INTO REGIONAL DEVELOPMENT

ISSN 2669-0195 (online) http://jssidoi.org/IRD/

2021 Volume 3 Number 3 (September)

http://doi.org/10.9770/IRD.2021.3.3(6)

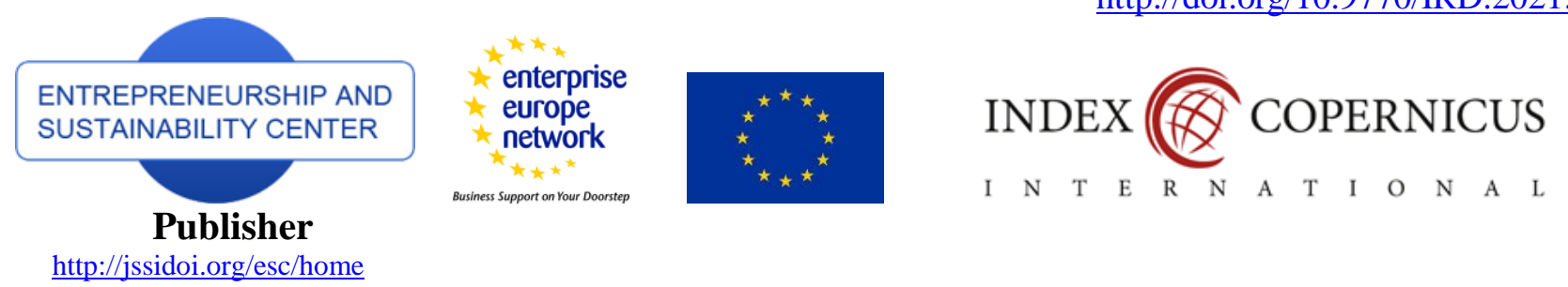

\title{
NET ENERGY AND FEASIBLE ECONOMIC GROWTH: A DEVELOPING COUNTRY PERSPECTIVE FROM INDIA
}

\author{
Ravi Prakash \\ Department of Mechanical Engineering, Motilal Nehru National Institute of technology, Allahabad (UP), India \\ E-mail: rprakash234@gmail.com
}

Received 15 May 2021; accepted 25 July 2021, published 30 September 2021

\begin{abstract}
The objective of this article is to highlight the significance of net energy consideration in economic policymaking, which has received less or no attention from the stakeholders particularly in the context of developing economies like India. With the rapid growth in the renewable energy sector, in this period of the low-carbon energy transition, there appears to be a growth in gross energy output. However, the net energy outputs reaching the demand sector of the economy may still be low due to the large feedback energy requirements for such rapid growth in energy supply. Such reduced energy availability may lead to reduced gross domestic product (GDP) growth unlike what is envisaged by policymakers. This is in contrast to the conventional standpoint, where assumed economic growth scenarios are used for energy planning. Since electricity use and economic development are found to be strongly correlated for developing economies like India, it is expected that a reduction in net energy available from the power sector will impose constraints on the GDP growth. Hence, a very ambitious electricity supply programme such as the one based on solar electricity may be counterproductive to GDP growth.
\end{abstract}

Keywords: net energy; developing economy; feasible GDP; electricity; energy planning

Reference to this paper should be made as follows: Prakash, R. 2021. Net energy and feasible economic growth: a developing country perspective from India. Insights into Regional Development, 3(3), 106-113. http://doi.org/10.9770/IRD.2021.3.3(6)

JEL Classifications: Q4, Q5

\section{Introduction}

Energy is the most important resource for the development and economic growth of a nation. The link between energy and economy may be understood by assuming a national economic system as an 'engine', whose total output is measured by the sum of goods and services produced within its boundaries i.e. the gross domestic product (GDP). The GDP, an index of economic output, is generated by the input of energy which drives the economic engine. The 'efficiency' of this economic engine represented as GDP per unit of energy consumption is dependent on climate (degree-days), structure of the economy, types of technology used, along with quantity and quality of the energy resources available in a country. Brown et al (2011) demonstrated "a positive relationship between energy use and economic growth through a statistical relationship by considering per capita energy consumption (E) for each country and per capita GDP for each country $(\mathrm{G})$ as a power law: $E=4.13 \mathrm{G}^{0.76}$." 


\section{INSIGHTS INTO REGIONAL DEVELOPMENT}

ISSN 2669-0195 (online) http://jssidoi.org/jesi/

2021 Volume 3 Number 3 (September)

http://doi.org/10.9770/IRD.2021.3.3(6)

It is worth noting here that while the economic output is dependent on the magnitude or quantity of energy available, the impact of 'quality' of energy resource being used is also significant. Petroleum is a more efficient fuel than coal for most purposes, as measured by both thermal and economic criteria. Electricity is an even higher quality resource than petroleum and coal. The higher quality of electricity is particularly useful in manufacturing where its conversion to mechanical work and heat at the point of application can be controlled exactly with respect to time and where power requirements could be matched to the task.

This study seeks to draw the attention of energy analysts and policy makers to the "net energy" constraints likely to be faced by developing economies like India in maintaining high GDP growth rates. This is in contrast to the conventional standpoint, where assumed economic growth scenarios are used for energy planning. The term "net energy" here refers to the energy available from an energy transformation system after subtracting the energy feedback required to construct and commission it. While appraising the role of energy in an economy, the critical parameter is net energy i.e. the energy reaching the demand sector of the economy. However, the net energy consideration has received little or no attention from the stakeholders particularly in the context of developing economies like India.

\section{Net energy analysis and its scope}

Energy analysis, earlier called energy accounting, was developed in order to quantify the energy required to produce a particular item by establishing all the contributions to it which themselves require energy. It accounted for the extraction and refining of raw materials, transportation to the place of use, energy required for the construction and operation of plant, delivery of the finished product and so on. The concept gained popularity in the early 1970's, and led to an international workshop in 1974 under the auspices of the International Federation of Institutes for Advanced Study (IFIAS), Sweden, to establish methodology and conventions of energy analysis. According to the IFIAS workshop report - "Energy Analysis is defined as the determination of the energy sequestered in the process of making a good or service within the framework of an agreed set of conventions or applying the information so obtained" (Energy Analysis Workshop, IFIAS, 1974). The energy analysis evaluates the total quantity of energy that has to be sequestered from primary energy resources in order to produce a specified commodity and service - called the 'gross energy requirement' (or GER) of the commodity or service. The analysis includes the direct use of energy in the production process and also the energy used to produce materials and machines used in the process. The sum total of such direct and indirect energy requirements of a product is also called its 'hidden' or 'embodied' energy.

The aims of energy analysis are many and various; they may be summarized as follows:

(a) To analyse the energy consumption of the different sectors of an economy to assist the forecasting of the total energy demand or point to policies which would reduce demand.

(b) To assist economic analysis in enabling it to predict the effect of fuel price increases on the price of manufactured goods.

(c) To determine the direct and indirect energy inputs in various industries, so to assess the most energy intensive industries as well as recommend energy conservation measures in such industries.

(d) To determine the most energetically favourable of several possible energy sources, and to identify 'point of futility' where no net energy is produced from a possible source of energy.

There can be no more appropriate field of application of energy analysis than in the case of energy industries themselves, for such an analysis addresses the question of whether it is worth investing energy for the energy one gets out of the investment. Energy analysis applied to energy transformation systems is called "net energy analysis" or NEA. 
'Net Energy' is defined as the energy available from an energy transformation system after subtracting the energy investment in the system. It is the net energy yield which measures the true value of the resource to society. The concept of net energy is explained through Figure 1. The energy feedback ' $F$ ' is necessary to develop the resource ' $R$ ' and produce a gross energy output ' $G$ '. The net energy is the difference between the two: $N=G-F$.

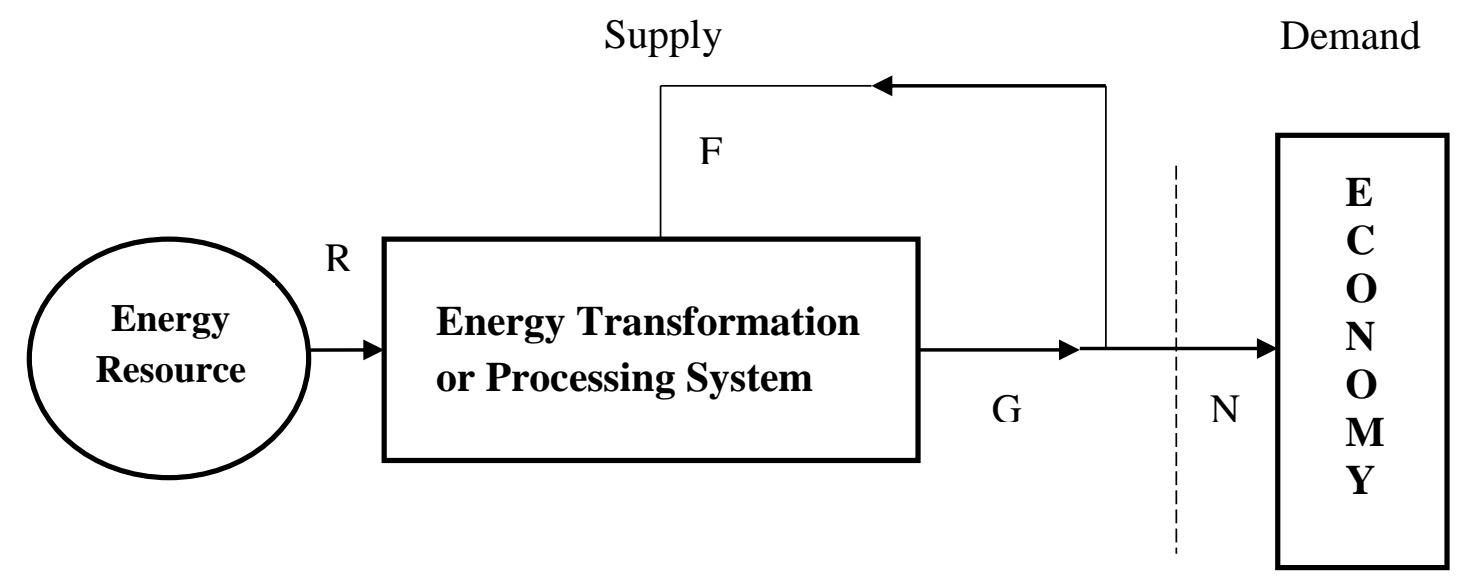

Figure 1. Net Energy Concept (Slesser, 1978)

The energy subsidy or feedback, F, includes both direct and indirect energy investments required by the energy transformation or processing system. Thus ' $\mathrm{F}$ ' includes inputs not only as direct fuels and electricity but also as energy associated with non-energy inputs.These can be many and various depending on system boundary assumptions, including energy for research and development, exploration, buildings, equipment, materials etc for initial and operational phases, decommissioning, labour in various guises, and the restoration of ecological side effects. This feedback ' $F$ ' reduces the gross output of energy to a net amount ' $N$ ' available for the demand sector.

The ratio "Energy Returned on Energy Investment" (EROI) equals G/F; this quantifies the number of units of gross energy produced per unit of energy feedback to the process. Here both $G$ and $F$ are expressed in energy equivalents of the same type. The EROI is meant to interpret the importance of an energy source to the economy. High ratios mean that the source can support the development of more activity in the economy. When the yield ratio is small, there is little energy to support activity other than that which supplies the necessary feedback. The same basis can be used to evaluate measures proposed to conserve energy. The feedback required for conservation service such as providing housing insulation or improving car efficiencies can be evaluated in energy cost. Energy savings can then be compared with the energy feedback in the savings effort (where both are expressed as energy equivalents of the same quality). If the ratio of savings to feedback is greater than one, there is a net energy contribution.

Energy conversion plants change a natural energy flow (such as sunlight) or the energy locked in a raw material (such as coal) into a form that can be conveniently used by a consumer. It is naturally important that an energy conversion plant e.g. that used for power generation delivers more energy over its operating life than that invested in constructing, commissioning, and maintaining it.

The static energy analysis examines the energy profitability of a single energy conversion plant. It tells whether the operational life of an energy conversion plant is more than its 'energy payback time'. The energy payback time is defined as the length of time during which a plant must operate to generate a quantity of energy equivalent to the amount of energy expended in its construction. 


\section{INSIGHTS INTO REGIONAL DEVELOPMENT}

ISSN 2669-0195 (online) http://jssidoi.org/jesi/

2021 Volume 3 Number 3 (September)

http://doi.org/10.9770/IRD.2021.3.3(6)

The dynamic energy analysis examines the energy profitability of a programme of several energy conversion plants. Often more than one plant is required to satisfy the projected demand for energy. The energy demand may grow linearly with time, but often these estimates of future demand display a good approximation to exponential growth: the projected demand increases each year by the fixed percentage of the demand of the previous year. A programme of plant construction and operation intended to produce, for example, an exponentially increasing amount of energy output, needs to be analysed to answer the following questions:

(a) How much time does it take before a programme of several such plants has produced more cumulative energy than it has consumed?

(b) What fraction of the energy output of such a programme must be offset against energy needed for continual investment in that programme?

(c) What is the net energy output from the programme in a particular year, i.e. the annual energy output after subtracting that needed for investment?

To summarize, net energy relates the economy's need for energy to the energy expenditure required to meet that need; and provides a comparison of various energy sources based on their ability to render useful work to the society (Poldy, 2008; Carbajales-Dale, 2014).

\section{The electricity-economy link for developing economies like India}

It is widely accepted that electricity (the highest grade of energy) is an essential input for economic growth, especially for developing economies like India. Burke et al (2018) provide macro-level evidence on the importance of electricity for economic development. They found that electricity access and use are strongly correlated with economic development. In developing countries, electrical power is acknowledged as an engine for growth and an essential infrastructure for development. Government policies have generally encouraged the rapid expansion of the electricity sector both by financial assistance to construction of generating facilities and by financing operating deficits stemming from subsidized tariffs. The common situation in the developing world is for electricity consumption to be supply constrained; more electricity would be consumed if more could be produced.

In developing countries, there is a large and significantly unsatisfied demand for exactly the kind of services that can best be provided by electricity. The tendency to consume more electricity as incomes rise is related to qualityof-life improvement of the population. Population levels determine electricity demand in a straight forward way, and the bulk of the global population increase is taking place in the developing world. The role of electricity in such economies will further enhance in the coming decades due to increasing prospects of electrification in the automobile, domestic, and industrial sectors.

The electric vehicles for transport of goods and passengers through road as well as a highly electrified rail network is leading to increased pressures on electricity supply. Other reasons for high electrical intensity in developing economies include lesser efficiency of the electrical equipment requiring more electricity per unit of output compared to those in the developed countries, as well as increasing electrification of agricultural operations e.g. water-lifting, harvesting, grain thrashing etc, which were earlier totally animal/human powered. The needs for better process control and, in some cases, for cleanliness have meant a greater range of applications for electricity throughout industry. More important are new materials processing techniques, such as electric arc furnaces to make steel that have shifted the heat-electricity balance towards electricity. Aluminium smelting, electrolysis, plasma arc and other forms of electrical melting, and certain chemical, glass and ceramic processes are notable. 


\section{INSIGHTS INTO REGIONAL DEVELOPMENT}

ISSN 2669-0195 (online) http://jssidoi.org/jesi/

2021 Volume 3 Number 3 (September)

http://doi.org/10.9770/IRD.2021.3.3(6)

In general, one may say that a strong electricity-economy link exists for developing economies and they represent high electricity intensiveness. Due to the pervasive and critically important role of electricity in developing countries, the accelerated economic growth of such countries would be crucially dependent on future electricity supplies.

In India's context, Prakash (2018) observed the following: "an exponential growth in electricity demand is being witnessed due to pressures of maintaining high economic growth rates and of improving the quality of life of an exponentially rising population. Though electricity intensiveness of the economy has apparently decreased in the last seven decades, the electricity growth requirements will still be high in order to maintain high GDP growth rates". It is not yet known with any certainty if this drop in electricity intensiveness over the years is due to electricity conservation efforts or structural changes in the economy or a combination of both. As a signatory to the Paris Climate Change Agreement, "India has committed to base $40 \%$ of its power generation capacity through renewable energy as well as reduce its carbon intensity of GDP by 33-35\% from 2005 levels by 2030" (Report of the Expert Group on $175 \mathrm{GW}$ RE, 2015). Installation of $175 \mathrm{GW}$ of renewable energy is to be achieved by 2022 , with projected capacity expansion up to $450 \mathrm{GW}$. Thus, the country is proceeding with rapid growth in the electricity supply sector particularly through solar and wind energy utilization.

\section{Net energy implications for economic growth}

Many studies have been reported globally relating to net energy or EROI since the 1970s. However, for contemporary significance, some recent and important studies further point to the implications of net energy for the economy. These studies are relevant in the current era of low carbon energy transition with enhanced focus on the growth of the renewable energy sector in order to limit global warming as per international agreements.

Sgouridis et al (2016) point out that "the sustainable energy transition requires energy to construct the necessary renewable energy infrastructure. This requirement is analogous to 'the sower's strategy', the long-established farming practice to save a fraction of the current year's harvest as seeds for the next. Fossil fuels are finite but we can 'sow' what these fuels provide: energy and minerals to create the capital needed for the transition". An exhaustive review of scientific literature on the EROI of renewable energy sources has been presented by Rana et al (2020) for solar PV, wind energy and bio-fuels as an aid to policy formulation.

A dynamic EROI assessment of the IPCC (Intergovernmental Panel on Climate Change) $21^{\text {st }}$ century electricity production scenario has been presented by Neumeyer and Goldston (2016). They observed that "the energy required to install and operate the infrastructure can be significant, especially at high rates of expansion, and has not been included explicitly in the overall IPCC scenario assessment". Capellan-Perez et al (2019) indicate that "a fast transition achieving a 100\% renewable electric system globally by 2060 consistentwith the Green Growthnarrative could decrease the EROI of the energy system to levels well below that required to sustain industrial complex societies".

A novel concept of green EROI has been presented by Moriarty and Honnery (2019) by "considering the ecosystem maintenance energy in addition to the conventional energy feedbacks, which cautions that global net energy produced in an ecologically sustainable manner will start falling in a decade or so." An optimistic perspective on EROI of future renewable energy growth has been presented by White and Kramer (2019); "with a distinction between a physical EROI and an economic EROI-appropriate at the level of the whole economy. This distinction leads them to conclude that a renewable future is possible. Such a future is essentially unconstrained by the physical EROI and will have an acceptable economic EROI-not much different from that of the past century". 


\section{INSIGHTS INTO REGIONAL DEVELOPMENT}

ISSN 2669-0195 (online) http://jssidoi.org/jesi/

2021 Volume 3 Number 3 (September)

http://doi.org/10.9770/IRD.2021.3.3(6)

In India's context, both the static and dynamic energy analyses were carried out earlier for nuclear power as well as solar PV based power. For India's nuclear power programme (Prakash and Henham, 1993), planned to grow at $16 \%$ during the 1990s, the energy payback time was evaluated as 22.5 years. This was due to the annual energy investment required to sustain the programme being as high as $91 \%$ of the annual energy output of the programme. For the solar PV power generation (Prakash and Bansal, 1995) based on mono-Si modules manufactured in India, "the critical growth rate was evaluated as $21 \%$; beyond which the programme would become an energy sink rather than a source". A more recent study by Jain et al (2018) for India indicates that "building a PV system large enough to meet the nation's entire electricity demand by 2050 is possible; however, it will require substantial electricity investment from existing electricity supply, leading to a short term electricity shortage".

Of course, similar studies need to be carried out for wind energy and other renewable energy technologies being deployed in India. It may be pointed out here that the dynamic energy analyses cited above are different in nature to the one presented by Steffen et al (2018). They point out the potential increase in EROI values with time, obtained from static net energy analyses with technological improvements projected until 2040. Of course, any potential increase in EROI values of a single energy conversion plant will also result in higher net energy availability from a programme of several energy conversion plants, provided its growth rates are not in the critical range.

The impact of net energy on the developing economy of India is not available in the literature. However, such studies undertaken for a few other regions in the world may provide some useful indications. Slesser (1978) reported on the dynamic energy analysis of the EEC's energy transition programme (1973-85), which aimed at reducing EEC's dependence on imported oil by the use of indigenous resources and a major shift to nuclear electricity. The study shows that the net energy available to the demand sector from such an energy transition rises by only $2 \%$ a year and not the $3.5 \%$ envisaged on primary energy basis. Thus a 'feasible' GDP growth (in constant money units) of about $25 \%$ was predicted from 1973 to 1985 . Peet et al (1987) examined the feasibility of "sustained economic growth" for New Zealand from net energy considerations, and found some evidence to the contrary. Shaw et al (2010) recommend net energy output (and not the gross energy output) as a base for policy instruments to promote renewable energy for increasing energy security. Lambert et al (2014) examined the correlation between EROI and "quality of life" indices such as the HDI. They observed that large-scale introduction of renewable energy generation may have too low an EROI and may prove too expensive to facilitate continued growth in developing economies.

Depending on the nature of the link between net energy (or net electricity) and economic growth for a country, net energy supplies may impose varying constraints on the economic growth envisaged such as for a developing economy like India. A rapid growth in electricity supply may require huge initial energy investments, thereby reducing the net energy reaching the demand sector of the economy. On the other hand, a slow growth in electricity supply may not provide sufficient momentum required for the economic growth envisaged.

\section{Conclusions}

This study points out that disregarding net energy constraints in policy making may lead to unintended consequences for the economy of a developing country like India. Since electricity use and economic development are found to be strongly correlated, it is expected that a reduction in net energy available from the power sector will impose constraints on the GDP growth. Hence, a very ambitious electricity supply programme such as the one based on solar electricity may be counterproductive to GDP growth.

However, a need exists for a closer examination of net energy-economy link through theoretical frameworks and empirical evidence, especially for developing economies. An enquiry related to this examination is - what would 


\section{INSIGHTS INTO REGIONAL DEVELOPMENT}

ISSN 2669-0195 (online) http://jssidoi.org/jesi/

2021 Volume 3 Number 3 (September)

http://doi.org/10.9770/IRD.2021.3.3(6)

be the nature of this link with ongoing technological improvements and structural changes in an economy? It may further be assessed if net energy availability is correlated with variations in GDP growth such as those recently witnessed for India.

Here, one may argue about the potential embodied energy gain through imports (if any) of power generating systems or its components such as solar PV panels. However, any such imports will have to be matched with exports, which will have their own embodied energy. Hence, energy tied up with imports and exports for an economy also needs to be taken into consideration during net energy evaluations. Further, an increased dependence on imported solar equipment similar to petroleum imports may compromise the energy security of the nation, and would lead to moving away from the goal of self-reliance.

If net energy constraints do lead to low GDP growth rates or perhaps a contraction of the economy, can we transcend this situation into an opportunity for expansion in "non-material" or intangible aspects of development such as cleaner air, better healthcare, and happier societies? It is likely that net energy constraints will force us to shift our focus from GDP growth to a more holistic progress. Let us seize this opportunity for a better future!

\section{References}

Brown, James H; Burnside, William R; Davidson, Ana D; DeLong, John P; Dunn, William C; Hamilton, Marcus J; Mercado-Silva, Norman; Nekola, Jeffrey C; Okie, Jordan G; Woodruff, William H; Zuo, Wenyun. (2011). Energetic Limits to Economic

Growth. BioScience, 61(1), 19-26. https://doi.org/10.1525/bio.2011.61.1.7

Burke, Paul J; Stern, David I; Bruns, Stephan B. (2018). The Impact of Electricity on Economic Development: A Macroeconomic Perspective. International Review of Environmental and Resource Economics, 12(1), 85-127. http://dx.doi.org/10.1561/101.00000101

Capellán-Pérez, Iñigo; Castro, Carlos de; González, Luis Javier Miguel. (2019). Dynamic Energy Return on Energy Investment (EROI) and material requirements in scenarios of global transition to renewable energies. Energy Strategy Reviews, Volume 26, 100399, ISSN 2211467X, https://doi.org/10.1016/j.esr.2019.100399

Carbajales-Dale, M., Barnhart, C., Brandt, A. et al. (2014). A better currency for investing in a sustainable future. Nature Climate Change 4, 524-527. https://doi.org/10.1038/nclimate2285

Energy Analysis Workshop on Methodology and Conventions: 25th-30th August 1974, Guldsmedshyttan, Sweden. (1974). Sweden: International Federation of Institutes for Advanced Study (IFIAS).

Jain, Sourabh; Jain, Nikunj Kumar; Vaughn, W. Jamie (2018). Challenges in meeting all of India's electricity from solar: An energetic approach. Renewable and Sustainable Energy Reviews, 82(1), 1006-1013, ISSN 1364-0321, https://doi.org/10.1016/j.rser.2017.09.099.

Lambert, Jessica G; Hall, Charles A.S;Balogh, Stephen; Gupta, Ajay; Arnold, Michelle. (2014). Energy, EROI and quality of life. Energy Policy, 64, 153-167.https://doi.org/10.1016/j.enpol.2013.07.001

Moriarty, Patrick; Honnery, Damon. (2019). Ecosystem maintenance energy and the need for a green EROI. Energy Policy, 131, 229-234, ISSN 0301-4215. https://doi.org/10.1016/j.enpol.2019.05.006

Neumeyer, Charles; Goldston, Robert. (2016). Dynamic EROI Assessment of the IPCC 21st Century Electricity Production Scenario. Sustainability 8(5), 421. https://doi.org/10.3390/su8050421

Peet, N.J; Baines, J.T; Macdonald, M.G; Tohill, J.C; Bassett, R.M. (1987). Energy supply and net energy in New Zealand. Energy Policy, 15(3), 239-248.https://doi.org/10.1016/0301-4215(87)90085-1

Poldy, Franzi. (2008). Net energy and strategic decision-making, Wiley Online, Biofuels, Bioprod. Bioref. 2, 389-392.

https://doi.org/10.1002/bbb.94

Prakash, Ravi (2018). A. Sayigh (ed.), Transition Towards 100\% Renewable Energy, Springer International Publishing AG. https://doi.org/10.1007/978-3-319-69844-1_31 
INSIGHTS INTO REGIONAL DEVELOPMENT

ISSN 2669-0195 (online) http://jssidoi.org/jesi/ 2021 Volume 3 Number 3 (September)

http://doi.org/10.9770/IRD.2021.3.3(6)

Prakash, Ravi; Bansal, N. K (1995). Energy Analysis of Solar Photovoltaic Module Production in India. Energy Sources, 17(6), 605613.https://doi.org/10.1080/00908319508946107

Prakash, Ravi; Henham, Alex. (1993). Energy analysis of India's nuclear power programme. Pacific and Asian Journal of Energy, 3(1), 147-158. http://epubs.surrey.ac.uk/id/eprint/851788

Rana, Roberto L.; Lombardi, Mariarosaria; Giungato, Pasquale; Tricase, Caterina. (2020). Trends in Scientific Literature on Energy Return Ratio of Renewable Energy Sources for Supporting Policymakers. Adm. Sci. 10(2), 21. https://doi.org/10.3390/admsci10020021

Report of the Expert Group on 175 GW RE by 2022 (2015), National Institution for Transforming India, Government of India, 2-3. https://niti.gov.in/writereaddata/files/175-GW-Renewable-Energy.pdf

Sgouridis, Sgouris; Csala, Denes; Bardi, Ugo (2016); The sower's way: quantifying the narrowing net-energy pathways to a global energy transition; Environmental Research Letters, Volume 11, Number 9. https://iopscience.iop.org/article/10.1088/1748-

9326/11/9/094009/meta\#

Shaw, Daigee; Hung, Ming-Feng, Lin, Yi-Hao (2010). Using net energy output as the base to develop renewable energy. Energy Policy, 38(11), 7504-7507.https://doi.org/10.1016/j.enpol.2010.06.051

Slesser, Malcolm (1978), Energy in the Economy, Macmillan Press, London, pp 137-153.

Steffen, Bjarne; Dominique Hischier, Dominique; Schmidt, Tobias S (2018). Historical and projected improvements in net energy performance of power generation technologies, Energy \& Environmental Science, Royal Society of Chemistry, 11, pp 3524-3530. https://pubs.rsc.org/en/content/articlepdf/2018/ee/c8ee01231h

White, Eoin; Kramer, Gert Jan. (2019). The Changing Meaning of Energy Return on Investment and the Implications for the Prospects of Post-fossil Civilization. One Earth, 1(4), 416-422. https://doi.org/10.1016/j.oneear.2019.11.010.

\section{Ravi PRAKASH}

ORCID ID: 0000-0001-7299-7725

Make your research more visible, join the Twitter account of INSIGHTS INTO REGIONAL DEVELOPMENT:

@IntoInsights

Copyright (C) 2021 by author(s) and VsI Entrepreneurship and Sustainability Center

This work is licensed under the Creative Commons Attribution International License (CC BY).

http://creativecommons.org/licenses/by/4.0/

CC) (i) Open Access 